\title{
The Effect of the Australian-Maritime Continents on the Indian Ocean Dipole Mode in an Idealized Coupled General Circulation Model
}

\author{
Tomomichi Ogata \\ Graduate School of Life and Environmental Sciences, University of Tsukuba, Tsukuba, Japan
}

\begin{abstract}
This paper investigates the effect of the Australian-maritime continents on the Indian Ocean Dipole (IOD) mode by using a coupled general circulation model (CGCM) under an idealized land-sea configuration. In such idealized CGCM experiments, the presence of the Australian-maritime continents increases the amplitude of the IOD between July and September. To determine the possible mechanisms associated with IOD enhancement by the Australian-maritime continents, the mean state during the boreal summer (austral winter) was compared from model runs both with, and without, the Australian-maritime continents. The presence of the Australian-maritime continents reduces rainfall during the austral winter, and generates an easterly (westerly) wind anomaly over the equatorial Indian Ocean (Pacific). These conditions are favorable for the development of a cooler SST and shallower thermocline, and hence enhance IOD amplitude through the thermocline feedback. In addition, a linear baroclinic model (LBM) experiment showed that the negative heating caused by the reduced rainfall over the Australian-maritime continents generates a significant easterly (westerly) wind anomaly over the equatorial Indian Ocean (Pacific) through the Matsuno-Gill response.

(Citation: Ogata, T., 2013: The effect of the Australian-maritime continents on the Indian Ocean Dipole mode in an idealized coupled general circulation model. SOLA, 9, 84-88, doi:10.2151/ sola.2013-019)
\end{abstract}

\section{Introduction}

The climate of the tropical Indian Ocean shows variability on various timescales (Schott et al. 2009), but one of the dominant features is the seasonal monsoon variability, which follows a distinct annual cycle over the northern Indian Ocean accompanied by southwesterly (northeasterly) winds in the boreal summer (winter). On interannual timescales, the Indian Ocean Dipole (IOD) mode, during which sea surface temperature (SST) is cooler (warmer) than the seasonal climatology in the eastern (western) equatorial Indian Ocean, is an important phenomenon (Saji et al. 1999; Webster et al. 1999; Ueda and Matsumoto 2000). The variability is seasonally phase locked, maturing during the boreal fall, before rapidly decaying in the winter. Such phase locking of the IOD is closely linked to seasonal migration of the Indian and Australian monsoon systems.

In the equatorial Indian Ocean, the existence of the Australian-maritime continents is believed to influence mean and interannual atmospheric circulations. For example, Kawamura et al. (2002) investigated the onset of the Australian monsoon during the austral summer and pointed out the importance of the air-sealand interaction. Chang and $\mathrm{Li}$ (2000) used a conceptual model to highlight the relationship between biannual monsoon variability and Indian/Austral monsoon circulation. While the easterly wind that develops during the boreal summer shoals the thermocline in the eastern equatorial Indian Ocean, and this provides favorable conditions for IOD events through the Bjerkness feedback. Abe

Corresponding author: Tomomichi Ogata, University of Tsukuba, Tennodai 1-1-1, Tsukuba, Ibaraki 305-8572, Japan. E-mail: ogata.tomomichi.ga @u.tsukuba.ac.jp. (C)2013, the Meteorological Society of Japan. et al. (2004) suggested an orographic effect on the global monsoon, in which the climatological features of the Asian summer monsoon and Indo-Pacific Walker circulation are enhanced by mountain uplift in CGCM experiments. However, the effect of the Australian-maritime continents on the IOD has yet to be clarified.

In this study, idealized CGCM experiments were used to determine the impact of the Australian-maritime continents on the IOD; in particular, the relationship between the mean state due to the Australian monsoon and its influence on IOD events is considered. Section 2 describes the detailed configurations of the CGCM. The results of the CGCM experiments, especially the IOD and mean state differences, are shown in Section 3, and the oceanic and atmospheric feedbacks in the mean state differences and its possible causes are investigated. To detect the importance of the Australian-maritime continents, LBM diagnosis is also used. Section 4 provides a summary of the findings.

\section{Models}

The CGCM used in this study was the University of Tokyo Coupled Model (UTCM: Tozuka et al. 2006). The atmospheric component of this model is based on the Frontier Atmospheric Model (FrAM: Guan et al. 2000), and the horizontal and vertical resolution was T21L20 $\left(5.625^{\circ}\right)$. The oceanic component is based on the Modular Ocean Model version 3 (MOM3: Pacanowski and Griffies 2000), with zonal and vertical resolutions of about $2.8^{\circ}$ and 25 levels, respectively. In the oceanic component, meridional resolution was gradually increased from $0.5^{\circ}$ to $2^{\circ}$ to resolve equatorial oceanic waves, and 10 levels were set in the upper 100 $\mathrm{m}$ to resolve thermocline variability. The model's land-sea configuration was set to the idealized Eurasian, African, North and South American continents, and the three basins of the Indian, Pacific, and Atlantic oceans (Fig. 1). Topographically, an idealized plateau was also included to simulate a realistic Indian and South Asian Monsoon. The UTCM was integrated for 160 years, with the last 130 years being used in this analysis. 30 years is long enough to spinup the upper level ocean model including the thermocline. The effect of the Australian-maritime continents was investigated by comparing two CGCM experiments: one experiment is without the Australian-maritime continents; i.e., where the ocean covered $120^{\circ} \mathrm{E}-150^{\circ} \mathrm{E}, 5^{\circ} \mathrm{S}-40^{\circ} \mathrm{S}$ (the noAUS run), and the other is with the Australian-maritime continents; i.e., land covered $120^{\circ} \mathrm{E}-$ $150^{\circ} \mathrm{E}, 5^{\circ} \mathrm{S}-40^{\circ} \mathrm{S}$ (the CTL run).

\section{Results}

Simulated mean state in the tropics is shown in Fig. 1. The CGCM simulates seasonal variation of rainfall, wind and SST well despite of highly idealized land-sea distribution (e.g. seasonal Indian Monsoon, cold SST tongue during boreal summer, meridional migration of precipitation such as south Pacific convergence zone; SPCZ). The CGCM also simulates qualitatively realistic seasonal migration of Indian and Australian monsoon. Sudden onset (June for Indian monsoon in both experiments, November for Australian monsoon in CTL run) is also captured. Even with the highly idealized land-sea distribution, many realistic and important climate features are simulated.

Figure 2 shows the regressed SST and wind stress pattern 
(a)

land-sea (noAUS)

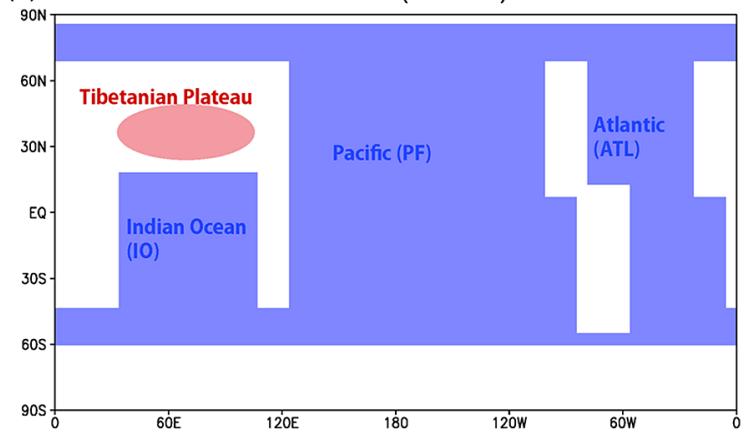

(b)

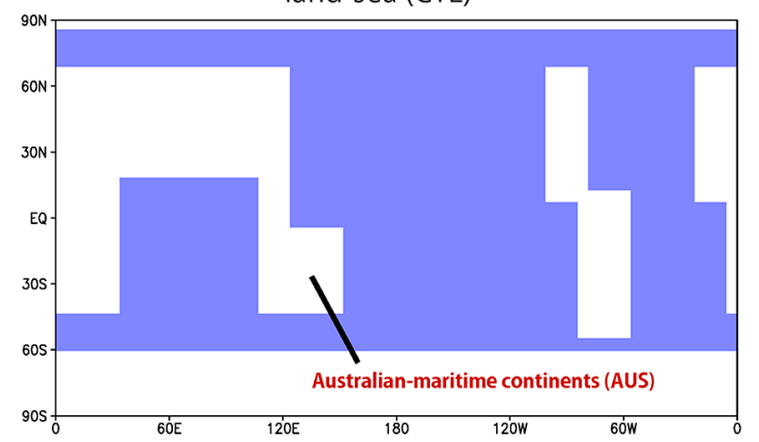

(c)

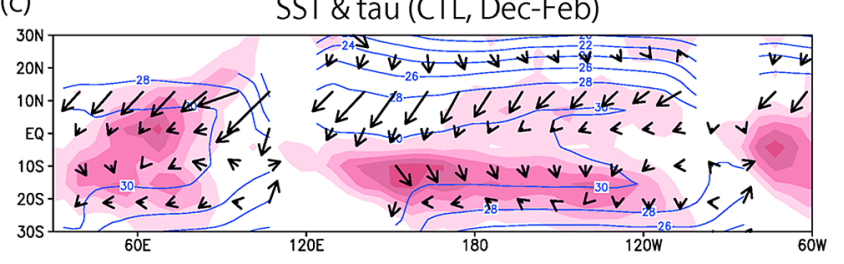

(d)

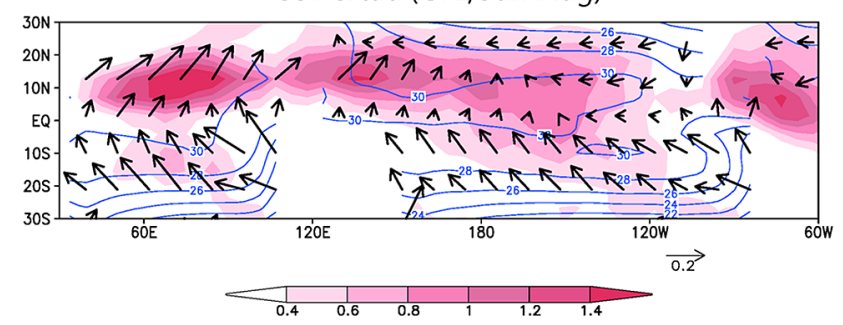

Fig. 1. Schematic representation of the model land-sea configuration in (a) noAUS and (b) CTL. Climatology of precipitation (shaded: $10^{-4} \mathrm{~mm} \mathrm{~s}^{-1}$ ), wind stress (vector: $\mathrm{N} \mathrm{m}^{-2}$ ) and SST (contour: ${ }^{\circ} \mathrm{C}$ ) in CTL during (c) December-February and (d) June-August.

for the SST anomaly over the eastern equatorial Indian Ocean $\left(85^{\circ} \mathrm{E}-105^{\circ} \mathrm{E}, 5^{\circ} \mathrm{S}-5^{\circ} \mathrm{N}\right)$ between July and September in the noAUS and CTL experiments. A cold (warm) SST anomaly appears over the eastern (southwestern) tropical Indian Ocean, and an anomalous easterly wind is dominant over the central equatorial Indian Ocean. Similar features occur in the observational data and other (more realistic) model simulations, despite the model's land-sea configuration being highly idealized. Furthermore, the resemblance of the SST and wind amplitude to an IOD-like pattern is stronger in the CTL run than in noAUS. For example, the SST (wind stress) anomaly is stronger in CTL by $2^{\circ} \mathrm{C}\left(0.2 \mathrm{~N} \mathrm{~m}^{-2}\right)$. This IOD-like SST anomaly matures from the boreal summer to the fall in both cases, consistent with previous observational and modeling studies (observed standard deviation of dipole mode index (DMI) from optimal interpolated SST (OISST; Raynolds et al. 2002) is about $0.6^{\circ} \mathrm{C}$ during July-November). According to spectrum analysis, period of IOD in the noAUS run is about $2-10$ (a)

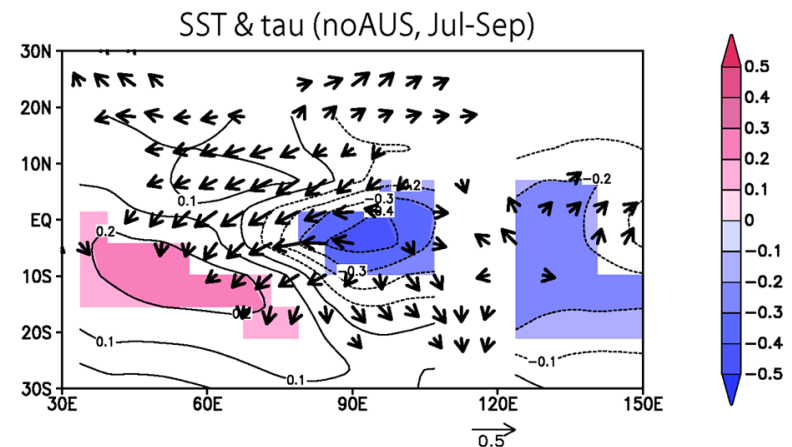

(b)

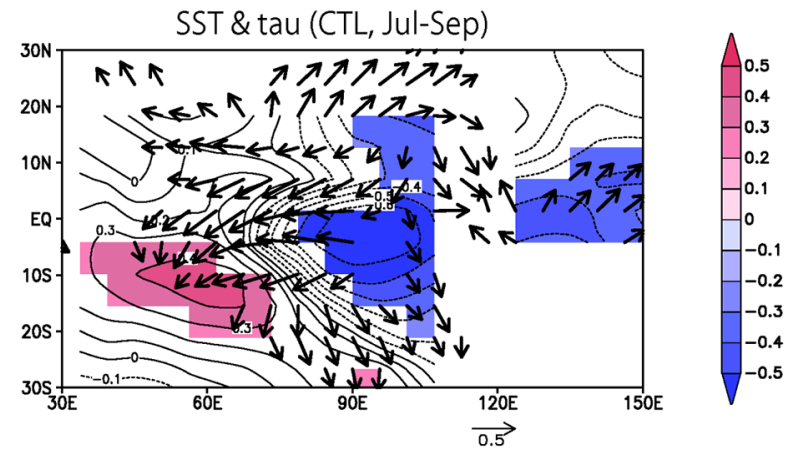

(c)

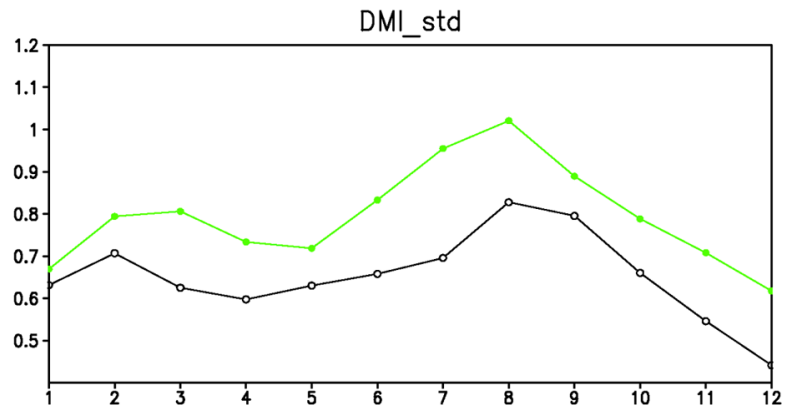

Fig. 2. Regression pattern of SST $\left({ }^{\circ} \mathrm{C}\right)$ and wind stress anomalies $\left(\mathrm{N} \mathrm{m}^{-2}\right)$ onto the SST anomaly for July-August over the eastern equatorial Indian Ocean $\left(85^{\circ} \mathrm{E}-105^{\circ} \mathrm{E}, 5^{\circ} \mathrm{S}-5^{\circ} \mathrm{N}\right)$ in (a) noAUS and (b) CTL. (c) Seasonal march of the standard deviation of the IOD in noAUS (black line) and CTL (green line). The IOD is defined as the western box $\left(45^{\circ} \mathrm{E}-65^{\circ} \mathrm{E}\right.$, $\left.5^{\circ} \mathrm{S}-15^{\circ} \mathrm{S}\right)$ minus the eastern box $\left(85^{\circ} \mathrm{E}-105^{\circ} \mathrm{E}, 5^{\circ} \mathrm{S}-5^{\circ} \mathrm{N}\right) \mathrm{SST}$ anomaly. In (a) and (b), shade and vector are plotted over regions with statistically significant at $90 \%$ level.

year (broad spectrum) and that in CTL run is about 4 year (sharp spectrum). However, the amplitude of the IOD-like SST anomaly in CTL is stronger than in the noAUS case (Fig. 2c). These results suggest that the presence of the Australian-maritime continents plays a key role in changing the IOD-like SST amplitude.

To investigate the causes of the amplitude change in IODlike SST between the two experiments, the climatological mean sea surface height ( $\mathrm{SSH}$ ) was compared from the two runs (SSH is a good indicator of thermocline variability). In the equatorial Indian Ocean, climatological SSH during the boreal summer in both experiments was higher (deeper thermocline) in the west, and lower (shallower thermocline) in the east (Fig. 3a). This oceanic mean state favors the development of the IOD through the thermocline feedback, acting between the shallow thermocline and SST. Furthermore, in CTL, this zonal SSH gradient was enhanced (Figs. 3b, c). This mean state change caused by the presence of the Australian-maritime continents is consistent with the enhancement of IOD amplitude through the intensified thermocline feedback caused by the shallower thermocline in the eastern Indian Ocean. In this experiment, southerly wind over the southeastern Indian Ocean generates coastal upwelling and shallow thermocline 
(a)

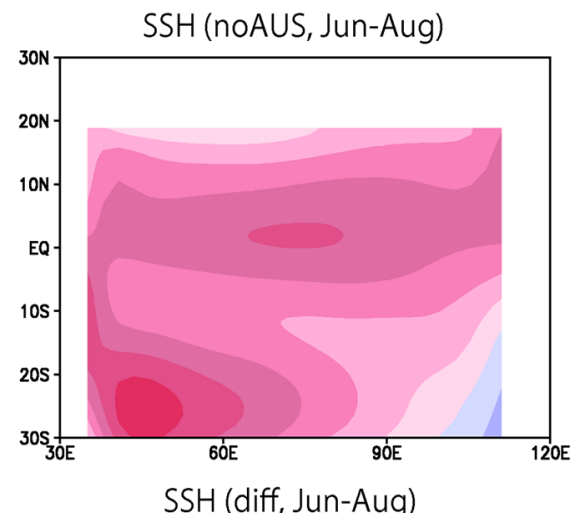

(b)

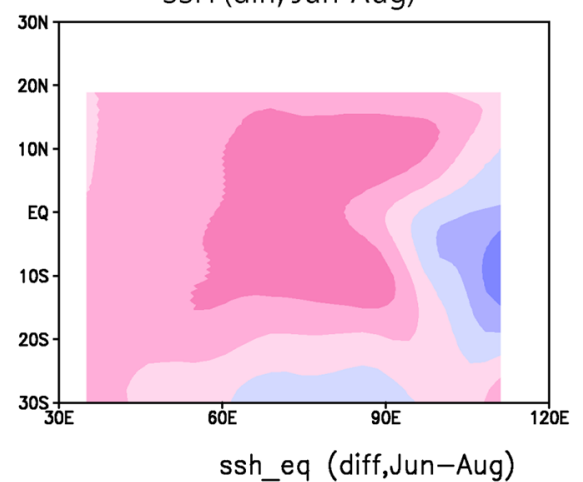

(c)

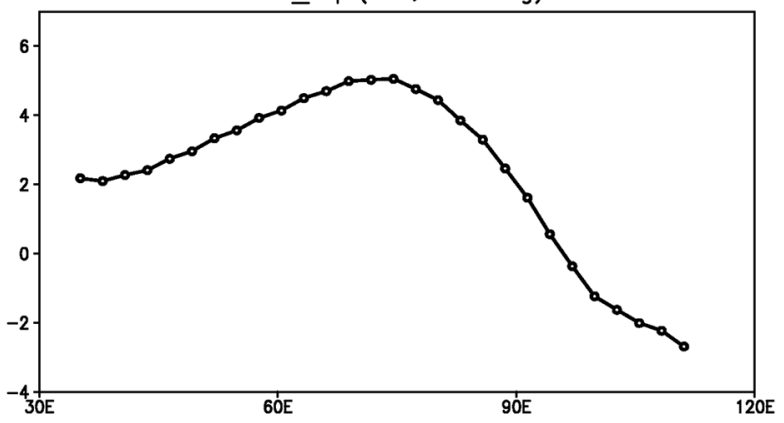

Fig. 3. (a) Mean SSH (cm) for July-August in noAUS. (b) SSH difference defined as CTL-noAUS. (c) Mean SSH difference over the equator.

during boreal summer, consistent with many observation and modeling studies. However such shallow thermocline (low SSH) is extended to the equator and thus may cause more sensitive thermocline feedback over the equator.

What causes this SSH difference when the Australian-maritime continents are incorporated into the model run? Figure 4 shows the SST, rainfall and wind stress difference between the noAUS and CTL cases. The presence of Australian-maritime continents induces cooling SST (Fig. 4a) and reducing rainfall (Fig. 4b) during the austral winter (June-August), and the associated divergent flow at the equatorial surface generates an easterly wind response in the Indian Ocean sector. The easterly wind response in this region is consistent with the zonal SSH gradient shown in Fig. 3; consequently, the positive air-sea feedback between the easterly wind response, thermocline shoaling in the eastern basin, and the cold SST anomaly is critical to explaining the IOD amplitude change generated by the presence of the Australian-maritime continents. In contrast, the divergent flow associated with the Australian monsoon generates a westerly surface wind response over the equatorial Pacific. From surface temperature and specific humidity, it is evident that the existence of the Australian continent causes dryer and colder surface condition in austral winter, which is favorable to enhance continental high (Figure not shown). It should be noted that the presence of the Australian-maritime continents also causes increased rainfall and cyclonic circulation (a)

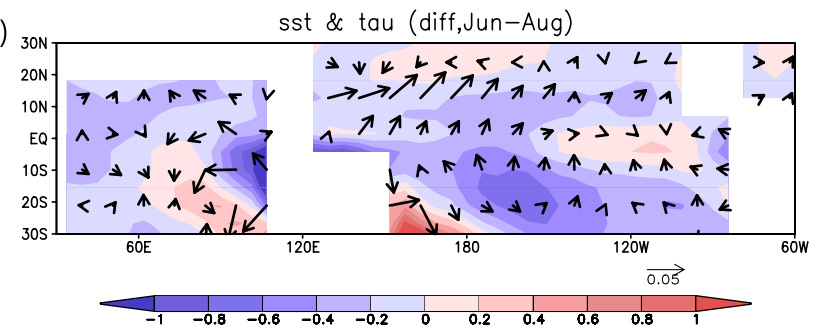

(b)

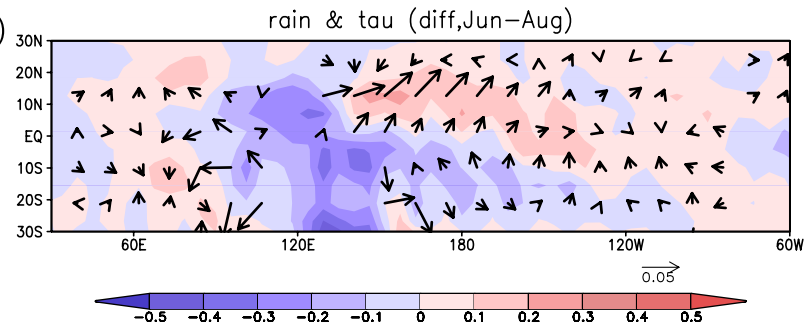

(c)

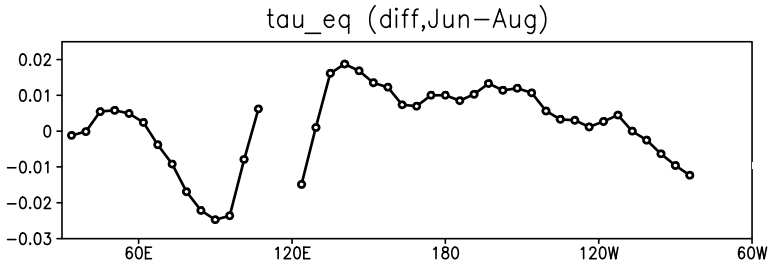

Fig. 4. (a) Mean SST (shade: ${ }^{\circ} \mathrm{C}$ ) and wind stress (vector: $\mathrm{N} \mathrm{m}^{-2}$ ) differences for July-August defined as CTL-noAUS. (b) As for (a) but for mean rainfall (shade: $10^{-4} \mathrm{~mm} \mathrm{~s}^{-1}$ ) and wind stress differences. (c) Difference in zonal wind stress over the equator.

in the northwestern tropical Pacific (Fig. 4b). This may be due to the surface convergence generated by the atmospheric Kelvin response (Xie et al. 2009).

Sensitivity experiments based on a linear baroclinic model (LBM) were used to investigate which region of atmospheric heating is most important in generating the easterly wind over the equatorial Indian Ocean seen in Fig. 4. LBMs are derived from the linearized atmospheric primitive equation using a sigma coordinate system, and the resolution was $2.5^{\circ}$ horizontally and 5 levels vertically. This model has been used in previous studies (Hirota et al. 2006; Ogata and Xie 2011), and the results explain both the observations and the underlying dynamical processes well. In this study, the rest background states (i.e., zero background velocity) were chosen, and the long-term mean of the zonally averaged equatorial thermal structure in the CGCM experiment (the noAUS run) was defined as a horizontally uniform stratification. Therefore, the response in the tropical heating is similar to the Matsuno-Gill response (Matsuno 1966; Gill 1980). Non-adiabatic heating was estimated from the rainfall difference between noAUS and CTL, and the heating region was separated into three sectors (IO region: $30^{\circ} \mathrm{E}-110^{\circ} \mathrm{E}$, AUS region: $110^{\circ} \mathrm{E}-150^{\circ} \mathrm{E}$, and $\mathrm{PF}$ region: $\left.150^{\circ} \mathrm{E}-300^{\circ} \mathrm{E}\right)$. Figure 5 a shows the zonal wind response in the LBM at the lowest level (sigma $=0.95)$ in each experiment. In the Indian Ocean sector, IO heating generates a weak easterly, but AUS heating is dominant and forms the easterly wind response. In the Pacific sector, PF heating generates a moderate westerly, but AUS heating is dominant and forms the westerly wind response. From the rainfall pattern in Fig. 4b, cooling due to the austral winter monsoon is dominant over the Australian-maritime continents. This cooling generates an asymmetric MatsunoGill response and associated divergent zonal circulation, which acts as a remote response to the Indian Ocean and Pacific sectors.

On the other hand, the Australian-maritime continents in the real world consist of the Australian continent $\left(10^{\circ} \mathrm{S}-40^{\circ} \mathrm{S}\right)$ and maritime continent (north of $10^{\circ} \mathrm{S}$ ). Especially, tropical circulation such as Walker circulation and Madden-Julian Oscillation is sensitive to the treatment of the maritime continent. This difference 
(a)

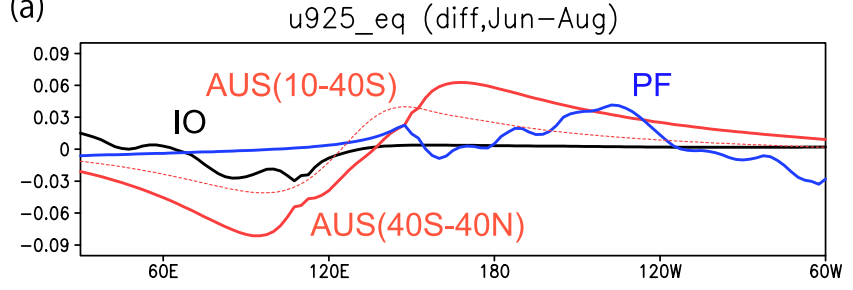

(b)

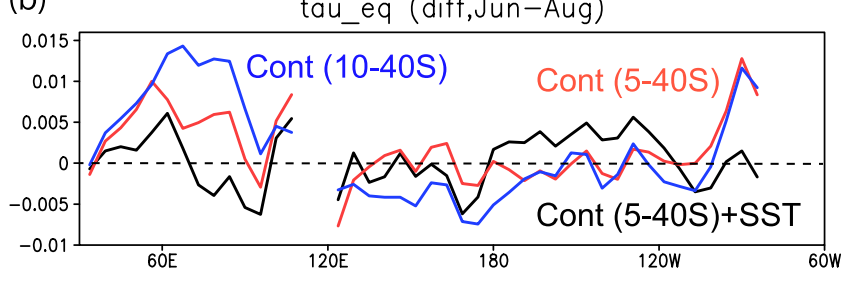

Fig. 5. (a) Zonal wind responses in LBM experiments over the equator at the lowest level $\left(\right.$ sigma $\left.=0.95: \mathrm{m} \mathrm{s}^{-1}\right)$ to thermal forcing estimated from rainfall differences (Fig. 4b). Responses to Indian Ocean heating $\left(30^{\circ} \mathrm{E}-\right.$ $110^{\circ} \mathrm{E}, 40^{\circ} \mathrm{S}-40^{\circ} \mathrm{N}$ : black line), Australian-maritime continents heating $\left(110^{\circ} \mathrm{E}-150^{\circ} \mathrm{E}, 40^{\circ} \mathrm{S}-40^{\circ} \mathrm{N}\right.$ : red line, and $110^{\circ} \mathrm{E}-150^{\circ} \mathrm{E}, 10^{\circ} \mathrm{S}-40^{\circ} \mathrm{S}$ : red dash line), and Pacific heating $\left(150^{\circ} \mathrm{E}-300^{\circ} \mathrm{E}, 40^{\circ} \mathrm{S}-40^{\circ} \mathrm{N}\right.$ : blue line). (b) Differences in zonal wind stress over the equator derived from AGCM experiments. REF1-noAUSa (CTL land-sea with noAUS SST: red line), REF2-noAUSa (CTL land-sea with CTL SST: black line), and REF3noAUSa (modified land-sea, e.g. Australian continent over $120^{\circ} \mathrm{E}-150^{\circ} \mathrm{E}$, $10^{\circ} \mathrm{S}-40^{\circ} \mathrm{S}$ with noAUS SST: blue line).

can potentially alter the results significantly. LBM experiments show that the zonal wind response over the equator is sensitive to the heating distribution. Easterly equatorial wind over the Indian Ocean is significantly weakened in Australian continent only case $\left(110^{\circ} \mathrm{E}-150^{\circ} \mathrm{E}, 10^{\circ} \mathrm{S}-40^{\circ} \mathrm{S}\right)$ compared to Australian-maritime continents case $\left(110^{\circ} \mathrm{E}-150^{\circ} \mathrm{E}, 40^{\circ} \mathrm{S}-40^{\circ} \mathrm{N}\right)$, suggesting the relative importance of the equatorial heating (Fig. 5a). Geopotential height response (Fig. S1) shows the symmetric Matsuno-Gill response in the maritime continent heating while asymmetric response in the Australian continent heating, which forms significant easterly over the Indian Ocean. It should be noted the cyclonic response in the northwestern Pacific heating (Fig. S1d), but the associated zonal wind response over the Indian Ocean is insufficient.

Furthermore, atmospheric general circulation model (AGCM) experiments with different boundary conditions (land-sea distribution and SST) are conducted. First, control run (hereafter noAUSa) is conducted with noAUS land-sea configuration and noAUS SST given by monthly CGCM climatology. For continental effect, reference run (hereafter REF1) is conducted with CTL land-sea configuration but keeping SST the same as in noAUSa (see also Table 1). Atmospheric component of UTCM was used and integrated for 20 years. The sensitivity experiments show that continental effect (under same SST condition; REF1-noAUSa) forms westerly over the equatorial Indian Ocean (Fig. 5b). Response in the zonal wind stress over the equatorial Indian Ocean between AGCM (Fig. 5b) and CGCM (Fig. 4c) is significantly different. Fixed SST in AGCM may cause the surface wind bias

Table 1. Land-sea and SST configurations in CGCM and AGCM experiments.

\begin{tabular}{lccc}
\hline & $\begin{array}{c}\text { Australia continent } \\
\left(120^{\circ} \mathrm{E}-150^{\circ} \mathrm{E},\right. \\
\left.10^{\circ} \mathrm{S}-40^{\circ} \mathrm{S}\right)\end{array}$ & $\begin{array}{c}\text { Maritime continents } \\
\left(120^{\circ} \mathrm{E}-150^{\circ} \mathrm{E},\right. \\
\left.5^{\circ} \mathrm{S}-10^{\circ} \mathrm{S}\right)\end{array}$ & $\mathrm{SST}$ \\
\hline noAUS & Ocean & Ocean & (coupled) \\
CTL & Land & Land & (coupled) \\
noAUSa & Ocean & Ocean & noAUS \\
REF1 & Land & Land & noAUS \\
REF2 & Land & Land & CTL \\
REF3 & Land & Ocean & noAUS \\
\hline
\end{tabular}

through precipitation or surface physics. For example, excessive rainfall in AGCM will generate stronger cyclone over the northwestern Pacific, and hence it may cause westerly wind bias over the equatorial Indian Ocean (Fig. S2). The different response between AGCM and CGCM may imply the importance of air-sea coupling. To quantify SST effect, another reference run (hereafter REF2) was conducted with the same land-sea configuration to REF1 but CTL SST given by monthly CGCM climatology. It should be noted that SST effect (REF2-noAUSa) forms easterly and is more influential to the mean state change over the equatorial Indian Ocean (Fig. 5b). AGCM result is also sensitive to the treatment of the maritime continent and additional experiments (continent over $120^{\circ} \mathrm{E}-150^{\circ} \mathrm{E}, 10^{\circ} \mathrm{S}-40^{\circ} \mathrm{S}$; hereafter REF3) show significant increase of westerly anomaly over the equatorial Indian Ocean (REF3-noAUSa in Fig. 5b). Rainfall difference shows the significant increase over the maritime continent in REF3-REF1, suggesting the westerly response through the stronger Walker circulation (Fig. S2b). Such mean state change will affect (perhaps reduce) the IOD amplitude change. As mentioned above, however, response between AGCM and CGCM is significantly different, so further study using CGCM will be needed.

\section{Summary}

The effect of the Australian-maritime continents on the IOD simulated by a CGCM under an idealized land-sea configuration was investigated. In the idealized CGCM experiments, the presence of the Australian-maritime continents increased the amplitude of the IOD between July and September. The relationships among SSH, SST, and surface zonal wind stress enhance the thermocline feedback when the Australian-maritime continents is present. In an attempt to identify the mechanism that induces IOD enhancement by the Australian-maritime continents, the mean state during the boreal summer (austral winter) was compared from runs with and without the Australian-maritime continents. The presence of the Australian-maritime continents reduced rainfall during the austral winter, and generated an easterly (westerly) wind anomaly over the equatorial Indian Ocean (Pacific). These conditions are favorable for the generation of a cooler SST and shallower thermocline, and hence enhance the IOD amplitude through the thermocline feedback. Furthermore, an LBM experiment showed that negative heating related to the reduced rainfall over the Australian-maritime continents generates a significant easterly (westerly) wind anomaly over the equatorial Indian Ocean (Pacific) through the Matsuno-Gill response.

For air-sea coupling processes in the IOD, the Bjerkness feedback (between SST and wind), and the thermocline feedback (between thermocline depth and SST) are key factors (Zheng et al. 2010; Ogata et al. 2013; Cai and Cowan 2013). Results from linear regression analysis suggest that the change in IOD amplitude is caused by the change in the thermocline-SST feedback (defined by the regression coefficient $R(\mathrm{SSH}, \mathrm{SST})$ ), while the SST-wind feedback strength $\left(R\left(\mathrm{SST}, \tau_{x}\right)\right)$ is similar in the CGCM experiments. It should be noted that the thermocline-SST feedback is more symmetric in the presence of the Australianmaritime continents, which is consistent with the findings of Ogata et al. (2013), who pointed out the more symmetrical form of the IOD in the easterly wind case.

The observed IOD events are sometimes induced by El-Niño and southern oscillation (ENSO). Thus, the change in the intensity of ENSO may cause the difference in the intensity of the IOD in this model. The relationship between ENSO and IOD as an inter-basin coupling is also investigated. Standard deviation of Nino3 $\left(5^{\circ} \mathrm{S}-5^{\circ} \mathrm{N}, 210^{\circ} \mathrm{E}-260^{\circ} \mathrm{E}\right) \mathrm{SST}$ anomaly in both experiments is almost similar (about $1.2^{\circ} \mathrm{C}$ ), which suggest that ENSO intensity is not crucial for the IOD amplitude difference. Correlation between IOD index and SST anomaly is also calculated. Correlation coefficient in both experiments is low in the eastern equatorial Pacific (less than 0.3), which suggest that ENSO is not a statistically significant trigger for IOD.

For mean state change in the equatorial Indian Ocean, Cai and 
Cowan (2013) also suggest the thermocline-SST-wind feedback mechanism in the mean state as an explanation for the overestimated IOD amplitude in the climate model intercomparison project phase 3 (CMIP3) and phase 5 (CMIP5) models. They pointed out that the positive feedback will enhance the mean state change if any single component (i.e., thermocline, SST, or wind) changes although the origin of this feedback remains unclear. The results of stronger IOD amplitude (Fig. 2) and the mean state change by the thermocline-SST-wind feedback (Figs. 3 and 4) are consistent with their study.

Finally, it should be noted that the result of AGCM and LBM experiments is sensitive to the treatment of the maritime continent (Fig. 5). Nevertheless, the result in this study seems still meaningful because the maritime continent consists of many islands and marginal seas, implying surface condition in this region is critical for the tropical circulation. From a view-point of paleoclimate, sea level during the Last Glacial Maximum (LGM) was about 100-150 m lower than present (Peltier 1994). Such sensitivity to the land-sea distribution may suggest some potential impacts of sea level change to the tropical air-sea circulation.

\section{Acknowledgements}

The author would like to appreciate thoughtful comments and suggestions by Hiroaki Ueda and Asuka Suzuki-Parker. UTCM source code was provided by Tomoki Tozuka and Takafumi Miyasaka. This work was supported by the SOUSEI Program of the Ministry of Education, Culture, Sports, Science, and Technology.

\section{References}

Abe, M., T. Yasunari, and A. Kitoh, 2004: Effect of large-scale orography on the atmosphere-ocean coupled system in the tropical Indian and Pacific sector in boreal summer. $J$. Meteor. Soc. Japan, 82, 745-759.

Cai, W., and T. Cowan, 2013: Why the amplitude of the Indian Ocean Dipole is overly large in contemporary climate models? Geophys. Res. Lett., 6, 1200-1205.

Chang, C.-P., and T. Li, 2000: A theory of the tropical tropospheric biennial oscillation. J. Atmos. Sci., 57, 2209-2224.

Gill, A. E., 1980: Some simple solutions for heat-induced tropical circulation. Quart. J. Roy. Meteor. Soc., 106, 447-462.

Guan, Z., S. Iizuka, M. Chiba, S. Yamane, K. Ashok, M. Honda, and T. Yamagata, 2000: Frontier Atmospheric General Circulation Model version 1.0 (FrAM1.0): Model climatology. Tech. Rep. FTR-1, 27 pp.
Hirota, N., M. Takahashi, N. Sato, and M. Kimoto, 2005: Recent climate trends in the East Asia during the Baiu season of 1979-2003. SOLA, 1, 137-140.

Kawamura, R., Y. Fukuta, H. Ueda, T. Matsuura, and S. Iizuka, 2002: A mechanism of the onset of the Australian summer monsoon. J. Geophys. Res., 107, D14, doi:10.1029/2001JD 001070.

Matsuno, T., 1966: Quasi-geostrophic motions in the equatorial area. J. Meteor. Soc. Japan, 44, 25-43.

Ogata, T., and S.-P. Xie, 2011: Semiannual cycle in zonal wind over the equatorial Indian Ocean. J. Climate, 24, 6471-6485.

Ogata, T., S.-P. Xie, J. Lan, and X. Zheng, 2013: Importance of ocean dynamics for the skewness of the Indian Ocean Dipole mode. J. Climate, 26, 2145-2159.

Pacanowski, R. C., and S. M. Griffies, 2000: MOM 3.0 manual. NOAA/GFDL, $680 \mathrm{pp}$.

Peltier, W. R., 1994: Ice age paleotopography. Science, 265, 195201.

Saji, N. H., B. N. Goswami, P. N. Vinayachandran, and T. Yamagata, 1999: A dipole mode in the tropical Indian Ocean. Nature, 401, 360-363.

Schott, F. A., S.-P. Xie, and J. P. McCreary, 2009: Indian Ocean circulation and climate variability. Rev. Geophys., 47, RG1002, doi:10.1029/2007RG000245.

Tozuka, T., T. Miyasaka, A. Chakraborty, M. Mujumdar, S. K. Behera, Y. Masumoto, H. Nakamura, and T. Yamagata, 2006: University of Tokyo Coupled General Circulation Model (UTCM1.0). Ocean-Atmosphere Research Rep. 7, University of Tokyo, $44 \mathrm{pp}$.

Ueda, H., and J. Matsumoto, 2000: A possible triggering process of east-west asymmetric anomalies over the Indian Ocean in relation to 1997/98 El Niño. J. Meteor. Soc. Japan, 78, 803818.

Xie, S.-P., K. Hu, J. Hafner, H. Tokinaga, Y. Du, G. Huang, and T. Sampe, 2009: Indian Ocean capacitor effect on Indo-western Pacific climate during the summer following El Niño. $J$. Climate, 22, 730-747.

Webster, P. J., A. Moore, J. Loschnigg, and M. Leban, 1999: Coupled ocean- atmosphere dynamics in the Indian Ocean during 1997-98. Nature, 40, 356-360.

Zheng, X.-T., S.-P. Xie, G. A. Vecchi, Q. Liu, and J. Hafner, 2010: Indian Ocean dipole response to global warming: Analysis of ocean-atmospheric feedbacks in a coupled model. $J$. Climate, 23, 1240-1253.

Manuscript received 8 March 2013, accepted 21 May 2013

SOLA: http://www.jstage.jst.go.jp/browse/sola 